NASA/TM-1999-208896
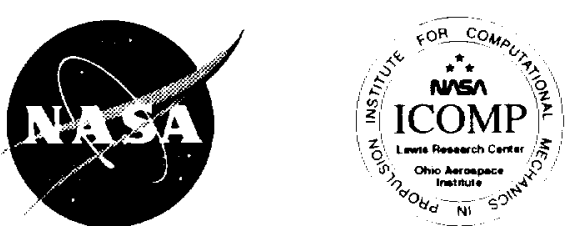

\title{
An Experimental and Numerical Study of Icing Effects on the Performance and Controllability of a Twin Engine Aircraft
}

\author{
A. Reehorst \\ Lewis Research Center, Cleveland, Ohio \\ J. Chung \\ Institute for Computational Mechanics in Propulsion, Cleveland, Ohio \\ M. Potapczuk and Y. Choo \\ Lewis Research Center, Cleveland, Ohio \\ W. Wright and T. Langhals \\ Dynacs Engineering Company, Inc., Brook Park, Ohio
}

Prepared for the

37th Aerospace Sciences Meeting \& Exhibit

sponsored by the American Institute of Aeronautics and Astronautics

Reno, Nevada, January 11-14, 1999

National Aeronautics and

Space Administration

Lewis Research Center 
Available from

NASA Center for Aerospace Information

7121 Standard Drive

Hanover, MD 21076

Price Code: A03

National Technical Information Service 5285 Port Royal Road Springfield, VA 22100 Price Code: A03 
AIAA 99-0374

\title{
AN EXPERIMENTAL AND NUMERICAL STUDY OF ICING EFFECTS ON THE PERFORMANCE AND CONTROLLABILITY OF A TWIN ENGINE AIRCRAFT
}

\author{
A. Reehorst \\ Icing Branch \\ National Aeronautics and Space Administration \\ Lewis Research Center \\ Cleveland, Ohio \\ J. Chung \\ Institute for Computational Mechanics in Propulsion \\ NASA Lewis Research Center \\ Cleveland, Ohio \\ M. Potapczuk and Y. Choo \\ Icing Branch \\ National Aeronautics and Space Administration \\ Lewis Research Center \\ Cleveland, Ohio \\ W. Wright and T. Langhals \\ Dvacs Engineering Company; Inc. \\ Brook Park, Ohio
}

\begin{abstract}
In September 1997 the National Transportation Safety Board (NTSB) requested assistance from the NASA Lewis Research Center (LeRC) Icing Branch in the investigation of an aircraft accident that was suspected of being caused by ice contamination. In response to the request NASA agreed to perform an experimental and computational study.

The main activities that NASA performed were LeRC lcing Research Tunnel (IRT) testing to define ice shapes and 2-D Navier-Stokes analysis to determine the performance degradation that those ice shapes would have caused.
\end{abstract}

An IRT test was conducted in January 1998. Most conditions for the test were based upon raw and derived data from the Flight Data Recorder (FDR) recovered from the accident and upon the current understanding of the meteorological conditions near the accident.
Using a two-dimensional Navier-Stokes code, the flow field and resultant lift and drag were calculated for the wing section with various ice shapes accreted in the IRT test. Before the final calculations could be performed extensive examinations of geometry smoothing and turbulence modeling were conducted.

The most significant finding of this effort is that several of the five-minute ice accretions generated in the IRT were found by the NavierStokes analysis to produce severe lift and drag degradation. The information generated by this study suggests a possible scenario for the kind of control upset recorded in the accident.

Secondary findings were that the ice shapes accreted in the IRT were mostly limited to the protected pneumatic boot region of the wing and that during testing, activation of the pneumatic boots cleared most of the ice.

"Copyright $(1) 1999$ by the American Institute of Aeronautics and Astronautics. Inc. No copyright is asserted in the United States under Title 17. U.S. Code. The U.S. Government has a royalty-free license to exercise all rights under the copyright claimed herein for Governmental Purposes. All other rights are reserved by the copyright owner." 


\section{Background}

In early 1997, a twin-engine commuter aircraft (Figure 1) crashed during a rapid descent after an uncommanded roll excursion. There were no survivors. The ground impact forces and post accident fire destroyed the aircraft. Instrument meteorological conditions prevailed at the time of the accident ${ }^{1}$. During the investigation, the National Transportation Safety Board (NTSB) contacted the Icing Branch at NASA Lewis Research Center. The NTSB requested NASA's participation since ice contamination was suspected as being a factor. NASA offered to pursue a study that included experimental and computational elements to identify the broad nature of possible ice contamination and the likely associated performance degradation.

\section{Project Methodology}

The primary goal of the NASA activity supporting the NTSB investigation was to attempt to identify a mechanism explaining the stability and control upset that preceded the accident. The methodology that was adopted to satisfy this goal was a multistep process that included both computational and experimental tasks.

The first step was to perform initial ice accretion predictions with the NASA LEWICE program to define the impingement limits and total mass of ice to be expected. Since the specific meteorological conditions at the time of the accident are unknown, the LEWICE calculations allowed the generation of ice shapes over the range of possible conditions.

The LEWICE calculations were followed by a test in the NASA Lewis Research Center's Icing Research Tunnel (IRT). The IRT testing was considered necessary since LEWICE, as with all ice accretion codes, does not model all of the physics of the accretion process. The complex movement of liquid water on the airfoil prior to its freezing is currently modeled by simplified relationships in all ice accretion codes. Due to this limitation and other assumptions required by ice accretion codes, the ice shapes predicted at temperatures near freezing are not always as accurate as those predicted for lower temperatures.
The contaminated airfoil geometries measured during the IRT test were then analyzed with a two-dimensional (2-D) Navier-Stokes code to predic their degraded aeroperformance. Due to the time constraints of this project, the icing wind tunnel test concentrated on measuring the ice accretion shapes, with all aerodynamic analysis performed computationally.

To verify that the 2-D analysis was producing realist $c$ results (that no significant threedimensional (3-D) flow effects were present), a limited 3-D Navier-Stokes analysis was conducted. The 3-D analysis was focused on assuring that no significant span-wise flow was present that would invalidate the chord-wise flow assumption required by the 2-D NavierStokes analysis.

\section{IRT Test}

The Icing Research Tunnel (Figure 2) is a closed-loop atmospheric tunnel with a test section that is $6 \mathrm{ft} \mathrm{high,} 9 \mathrm{ft}$ wide, and $20 \mathrm{ft}$ long. It is ec uipped to support testing at airspeeds from 50 to $430 \mathrm{mph}$ in a temperature and waterdrople environment that simulates natural icing conditions ${ }^{2}$. Temperature is controllable between -20 and $+33^{\prime \prime} F$. Clouds can be produced in a controlled manner with droplet mean volumetric diameter (MVD) between 9.5 and $270 \mu \mathrm{m}$.

For this lest an existing model was utilized. The model was a modified piece of wing from the subjec aircraft centered on the inboard region of the ailcron. The model had a 6-foot span and was mounted vertically in the IRT (Figure 3). The $w$ ng had a modified trailing edge and pneumatic boot. The trailing edge was faired behind the aft spar to avoid the mechanical complexity of the aileron. The pneumatic boot was $m$ dified for its original test to allow the incorp sration of thermal measurements. This featurt was not utilized for this subject testing, however, the modification resulted in the boot extending further aft on the lower surface than a production boot for this wing. This extended boot surface acted as an enhanced ice accretion locaticn that is evident when reviewing the test ice shape tracings. Except for the cases when the pneumatic boot was activated, the manufacturers recomnended level of vacuum was applied to 
the boot throughout the testing to prevent autoinflation. To ensure that the air temperature in the test section was accurate at the desired nearfreezing condition, an auxiliary temperature probe was mounted near the model and is visible in Figure 3.

\section{Test Environment Conditions}

Based upon the findings of the investigation's meteorological team ${ }^{3}$, the accretion time, the maximum liquid water content (LWC), and the cloud droplet's median volumetric diameter (MVD) were estimated for this test. The accretion time was estimated at 5 minutes. This was the length of time required by the accident aircraft to transit an area of low reflectivity evident on regional weather radar. This time also agrees with estimates based upon a measurable drag increase calculated by the investigation's performance team from flight data recorder (FDR) information ${ }^{4}$. The maximum LWC was estimated to be $0.8 \mathrm{~g} / \mathrm{m}^{3}$ based upon microwave radiometer measurements of the same airmass following the accident. The maximum MVD of the cloud droplets was estimated to be no greater than 70 to $80 \mu \mathrm{m}$. This droplet-sizing estimate was considered reasonable since the aircraft was known to have been in the clouds, and droplets larger than that are normally associated with below-cloud drizzle .

The remaining test parameters were defined based upon a combination of the accident meteorological data and the FDR information. The times that defined the assumed icing period from the meteorological report were used to access the pertinent information from the FDR. Representative airspeed, aircraft angle-of-attack and air temperature values were calculated by averaging over the assumed ice accretion period (total air temperature was derived from static air temperature measurements and corrected for altitude and airspeed, and wing angle-of-attack was calculated by adding the wing incident angle to the aircraft body angle-of-attack).

The combination of the assumed cloud conditions and the measured flight environment data was used to define the IRT test matrix (Table 1). Four conditions were considered the baseline series in the matrix. Due to uncertainties in the FDR measured values of angle-of-attack and temperature, additional series were added to the matrix that examined higher and lower angle-of-attack than the baseline value and higher and lower temperatures than that baseline value. An additional series with longer accretion time was also added since the ice accretion time was inferred information and not directly measured. A series of supercooled large droplet (SLD) conditions was added during the testing at the request of the NTSB to ensure the completeness of the database. To add to the level of confidence in the IRT results, all primary conditions were repeated at least once.

\section{Test Procedure}

The IRT test was conducted over two weeks in January 1998. The conditions described in Table 1 were used for this test and the most significant conditions were repeated at least once, as seen in Table 2. The normal process used during this test was to cool the IRT to the desired temperature and set the airspeed. When the temperature and airspeed were stable at the desired test conditions, the spray was activated for the length of time at air and water pressures defined by the test matrix to simulate a natural icing cloud. When the spray was shut off, several wake survey probe traverses were made behind the model. These wake probe traverses were used to calculate an uncorrected tunnel centerline section drag. Due to project time constraints, further correction, analysis, and comparisons of this data have not been completed. Following the wake probe traverses, the tunnel fan was stopped so that test personnel could enter the test section. Upon entering the test section, the test engineers would first photograph the model. Both digital and film cameras were utilized for this test, with the film photos typically being used for close-up detailed shots and the digital photos for overview shots (Figures 4 and 5). When the photographs were completed, the leading edge ice accretion was sliced with a hot knife, then traced onto a cardboard template (Figure 6). These tracings were made at 30,36 , and 42 inches from the wind tunnel floor (the 36 inch location is the vertical center of the test section). The ice shapes originally traced onto cardboard are then later digitized and stored electronically. All tracings presented here are digitized data 
(Figure 7). Three channels of video were also recorded for each ice accretion. The video cameras captured upper and lower leading edge views along with a broad model view. The video signals were recorded to SVHS format tapes.

\section{$\underline{\text { Resultant Ice Accretions }}$}

Repeatability was good for all cases, with the volume of ice, impingement limits, and horn or ridge location closely matched for repeat cases. The majority of the ice shapes accreted during this test fell into two categories. The first was a thin ice shape with a rough surface made up of small bumps of varying size and sharpness (Figure 8). The second category of ice shape had the same general volume of ice with similar roughness elements as the first category, but also a prominent ridge (Figure 9). This ridge was approximately 0.5 inches high.

The following is a description of the trends apparent in the test data:

- The baseline series ( see Table 1 ) resulted in thin ice accretions with distributed roughness and no ridge formation for all four of the series conditions (Figures 10 to 13).

- Compared to the baseline series, the higher angle-of-attack series (at 7 degrees instead of 5 degrees) produced ice shapes that were shifted towards the lower surface, as would be expected with this change of angle-ofattack (Figure 14). Since the upper impingement limit moved forward, the overall ice thickness of these shapes was somewhat greater than that seen in the baseline series.

- The lower angle-of-attack series cases (at 3 degrees instead of 5 degrees) were not significantly different than the baseline series.

- The higher temperature series cases (31 degrees Fahrenheit total temperature instead of 30 degrees) were not significantly different than the baseline series, but may have had a very slight decrease in the total volume of ice accreted.
- The lower temperature series (at 28 degrees F.threnheit total temperature instead of 30 digrees) produced slightly more total ice volume than the baselines series and more importantly started to exhibit some ridge formation for the 40 and $70 \mu \mathrm{m}$ MVD cases (Figure 15 and 16).

- The second lower temperature series (at 26 degrees Fahrenheit total temperature instead of 30 degrees) exhibited an ice ridge for all four conditions (Figures 17 to 20). The riilges apparent in these accretions are different from a standard horn formation in that they are surrounded by only a thin layer of ice, where a standard horn is part of a more substantial ice accretion. The ridge was most prominent for the two cases with LWC $=0.8 \mathrm{~g} / \mathrm{m}^{3}$ (matrix numbers 26 and 27. Figure 17 and 18). For the two cases with constant $\mathrm{LWC}$, the ridge moved aft with increasing MVD. For the two cases with censtant MVD, the ridge moved aft with in sreasing $\mathrm{LWC}$.

- In the longer time series (with an accretion time of 10 minutes instead of 5), selfshedding occurred in matrix number 32 (Figure 21). For the remaining cases in this series the ice mass was greater than in the baseline series, as would be expected. These shapes also exhibited a ridge fo mation (Figures 22 to 24). However th:se ridge formations appeared to be much more like a standard horn formation. These ice shapes were in general larger and rougher than those seen in the baseline series.

- The additional supercooled large droplet se ies (which extended the MVD up to 270 $\mu \mathrm{r}$ from the baseline maximum of 70 ) sh swed no significant difference in the leading edge ice accretion over those exaibited in the baseline series, except that the 175 and $270 \mu \mathrm{m}$ cases self-shed.

- Tre pneumatic boot was operated for several ca ies in the de-ice series. It was operated for the matrix number 3,26 , and 27 conditions. Depending on the case, the pneumatic boot was either activated at spray-off only (Figure 25), at two minutes into a fiveminute spray (Figures 26 and 27), or at 
two minutes and at spray-off (Figures 28 and 29). In all cases when the pneumatic boot was operated at the end of the icing spray, the leading edge ice shed very well. For the two cases when the boot was activated at two minutes into a five-minute spray, in one case it prevented the development of a ridge formation, and in the other case it did not. Whether the ridge was suppressed or not was probably dependant on how well the boot cleared the ice at the two-minute activation. It should be noted that the pneumatic boot used during this test was not a production boot and it had never experienced the operational environment. However, no special steps were taken to enhance the boot performance, such as the application of Ice-X, and it was operated at the same pressures as a flight system. The boot performance in the deicing tests is therefore considered to be broadly representative of that of a flight system.

The physics involved in the development of the ice ridges observed during this test are not well understood. It is very possible that the ridges are a result of the damming of surface runback water by ice feathers. The ridges appear to have formed at the aft edge of the primary ice accretion where ice feathers begin. Ice damming by ice feathers has been observed by close-up videography ${ }^{h}$, and may explain this form of ice growth. More research is required into the formation of the ice ridges seen in this test and, more generally, into the movement of liquid water on developing ice accretions.

\section{Computational Analysis}

The computational analysis performed as part of this effort is described in two AIAA reports ${ }^{7.8}$. The computational analysis consisted of both 2D and 3-D Navier-Stokes" computations. As described above, the performance of the icecontaminated wing was calculated via computational techniques instead of by experiment in order to complete the analysis in a timely manner for the NTSB investigation.

Four cases of the IRT ice shapes were selected for computational analysis based upon their varying nature. The ice shape from test matrix condition number 2 was selected since it exhibited a thin ice accretion with many small roughness elements. Matrix number 3 was also selected since it exhibited larger, sharper roughness elements than did matrix number 2 . Matrix number 9 was selected because it exhibited the roughness of matrix number 2 , but also had a larger accretion on the upper surface. Finally, the resultant ice shape form matrix number 26 was selected since it exhibited a significant ridge formation.

For the 2-D calculations, a significant effort was undertaken to determine the best level of ice tracing point smoothing and optimal grid point resolution $^{7 . k}$. The calculated lift curves of the four ice shapes examined compared to that of the clean airfoil are presented in Figure 30. As expected, when ice was added to the airfoil, the calculated lift was degraded. The matrix 2 shape had the least degradation since it had the lowest level of roughness of the shapes examined, followed by the matrix 3 shape, which had larger, rougher roughness elements. When the ice thickness increased, as in matrix number 9 , the lift degradation was further increased. The surprising result was the level of degradation when a ridged ice shape was examined. The major difference between the ice shape from matrix number 2 and that from matrix number 26 was the ice ridge. The roughness levels observed in the two cases were very close. When the ice ridge was present, a 45 percent reduction of maximum lift coefficient $\left(\mathrm{C}_{1 \text { max }}\right)$ was predicted in comparison to the clean airfoil. Since the ridged ice shape caused the greatest lift degradation, it was selected for all further computational analysis.

Of equal significance compared to the lift degradation caused by the ice contamination is the effect of aileron deflection for contaminated airfoils. Navier-Stokes calculations were performed for the wing in the configuration at the moment of the control upset. The moment of control upset was defined for this activity as the point when the aircraft's roll no longer tracked the aileron input. The roll angle and aileron (control wheel) position were recorded on the FDR (Figure 31.). The configuration of the aircraft with regards to bank and aileron position is shown in Figure 32. It should be noted that the aircraft flight variables of interest here (airspeed, angle-of-attack, altitude, and temperature) are different from those used to 
simulate the possible ice shapes in the IRT, since the accretion of ice and the control upset occurred at different times and spatial position.

When the aileron deflection effect was added to the degradation caused by the ridged ice shape the lift curves in Figure 33 resulted. The clean left wing (Clean $\mathrm{LW}$ ) line represents the lift curve for the airfoil with the aileron deflected down at 2.56 degrees. The clean right wing (Clean RW) line represents the lift curve for the airfoil with the aileron deflected up at 2.74 degrees. The left wing generates more lift than the right; therefore the aircraft will roll right. This was the intention of the pilot when these control inputs were made. However, with the ridged ice shape contamination on the wings, both the Iced LW and Iced RW lines show how the left and right airfoil lift curves were degraded. As angle-of-attack increases the differential lift decreases and at an angle-ofattack around 11 degrees the difference in lift between the two wings goes to zero. This degraded roll control authority is a possible answer as to why the aircraft continued to roll to the left when the aileron inputs were commanding a right roll.

At the completion of the 2-D analysis a limited 3-D analysis was undertaken ${ }^{8}$. The left wing geometry, including aileron deflection but minus engine nacelle, was applied to a 3-D structured grid. Developing a grid that accurately captured the wing geometry and also allowed the NavierStokes code to converge took a great deal of effort. To allow the convergence of the NavierStokes code in a timely manner the grid resolution used was relaxed. The resultant 3-D flowfield demonstrates a chord-wise flow over the wing. The trailing edge stall mechanism is also similar to that seen in the 2-D analysis, however, the stall occurred much more abruptly in 3-D than it did in 2-D. In 3-D the separation started right before the stall, but for 2-D the separation started several degrees before the stall. The angle-of-attack for stall in the 3-D analysis is also higher than that for the 2-D analysis. These differences may be caused by the relaxed grid resolution utilized for the $3-\mathrm{D}$ calculations. While explainable, the difference between the 2-D and 3-D results does warrant further investigation. A preliminary experimental comparison has also been made with results generated by the University of
Illinoi: at Urbana/Champaign"". While the airfoil used for the experiment was different than that used for this computational activity, the ice ridged shape was similar. The experimental stall angle is greater than that predicted by the NASA 2-D effort, but occurs due to trailing edge flow separation. The nature of the flow results appear to be similar to the NASA results, but as stated before more research will be required before the computational results can be utilized independently with complete confidence.

\section{Summary of Significant Experimental and Computational Findings}

The ic: shapes accreted during the IRT test largely fell into two categories. The first was a thin ic s shape with a rough surface made up of small sumps of varying size and sharpness. The second category of ice shape had the same general volume of ice with similar roughness elements as the first category, but also a prominent ridge. This ridge was approximately 0.5 inc hes high.

In all cases when the pneumatic boot was operal $2 d$ at the end of the icing spray, the leading edge i:e shed very well.

Of the four ice shapes analyzed with the NavierStokes code, the degraded $\mathrm{C}_{1 \text { max }}$ from the ice shape with the lowest level of roughness, matrix number 2, was about 75 percent of the clean airfoil. The $\mathrm{C}_{\mathrm{l} \text { max }}$ from the ice shape with larger, sharpe $r$ roughness elements, matrix 3 , was about 68 petcent of the clean airfoil. The $\mathrm{C}_{1 \text {. max }}$ from the ro igh shape with more ice accretion on the upper surface of matrix number 9 was about 60 percent of the clean airfoil. And the $C_{1, \max }$ from the ice ridge case, matrix 26 , was about 53 percent of the clean airfoil.

With the aileron effects added to the lift degralation caused by the ridged ice shape, the resultint lift curves for the left and right wing airfoils display that little or no lift difference may 1 ave been present and therefore roll control autho ity may have been significantly degraded.

While 3-D computational and experimental result ; do not directly confirm the 2-D NavierStoke ; results, they do confirm the general flow chararteristics, and stall mechanism. And 
enough differences exist between the 2-D and 3$D$ grids and the computational and experimental geometries to account for the differences in results.

\section{Concluding Remarks}

There are many lessons to be learned by this activity. The NASA Icing Branch has gained a significant amount of experience in measuring wind tunnel generated ice shapes and determining the aerodynamic performance for a contaminated wing. Along with this added knowledge have come more questions. What are the physical processes that led to the generation of the ridged ice shapes? How do varying ridge locations and heights influence airfoil and wing performance? How well do the Navier-Stokes codes compare to experimental aeroperformance data, and how can the agreement be improved? And, what is the best way of using the 2-D and 3-D codes together? There is a significant amount of work that needs to be accomplished before these question are answered and before we have a good understanding and confidence in all the methodologies.

The authors therefore recommend that the following activities be pursued:

- Additional testing be conducted to gain an understanding of the ice ridge formation process.

- More analysis and testing be conducted to understand the criticality of the ice ridge in regards to airfoil performance. This needs to include both ridge location and height.

- Compare the computational results from 2-D and 3-D Navier-Stokes code utilized to other Navier-Stokes codes using the same geometry and conditions.

- Aeroperformance testing and comparison to the Navier-Stokes solutions.

The other lessons learned through this activity relate to the operation of aircraft in icing conditions. Based upon the cockpit voice recorder from the accident aircraft, it appears that the flight crew was unaware of the potential hazard of their flight situation. While the total ice accretion was probably quite small, the aerodynamic effects appear to have been severe. For this incident, relying on past experiences and guidelines that suggested waiting until significant accretions existed before activating the pneumatic ice protection systems may have been a fatal error. Due to the limited information recorded, we will never be completely sure of the cause of this accident and can surely never know the level of awareness and intentions of the flight crew. However, based upon a review of the NASA results from this study along with the group consensus at a recent workshop ${ }^{11}$, two operational suggestions become apparent:

- Even ice accretions that may appear small and benign can be truly hazardous. Treat all icing conditions and resultant ice accretions as threats to your aircraft.

- Unless otherwise instructed by the aircraft flight manual, activate the ice protection systems at first indication of ice accretion; do not wait until a significant accretion has formed.

\section{$\underline{\text { References }}$}

1.) National Transportation Safety Board Aviation Accident Report, In-Flight Icing Encounter and Uncontrolled Collision with Terrain, Comair Flight 3272, Embraer EMB-120T, N265CA, Monroe, Michigan, January 9, 1997, NTSB Accident \# DCA97MA017.

2.) Soeder, Ronald H., Sheldon. David W., Andracchio, Charles R., Ide, Robert F. Spera, David A., and Lalli, Nick M.,"NASA Lewis Icing Research Tunnel User Manual", NASA TM-I07159, June, 1996.

3.) The Meteorological Group Chairman's Factual Report, NTSB Accident \# DCA97MA017.

4.) The Group Chairman's Aircraft Performance Study, NTSB Accident \# DCA97MA017.

5.) Personal communication with Marcia Politovitch and Ben Bernstein of the National Center for Atmospheric Research (NCAR), Decemher 1997.

6.) Hansman, R.J., et al.."Close-up Analysis of Aircraft lce Accretion", AIAA-93-0029. NASA TM-105952. January 1993. 
7.) Chung, J., Reehorst, A., Choo, Y., and Potapczuk, M.,'Effect of Airfoil Ice Shape Smoothing on the Aerodynamic

Performances", AIAA 98-3242, July 1998.

8.) Chung, J., Choo, Y., Reehorst, A., Potapczuk, M., and Slater, J.,"Navier-Stokes Analysis of the Flowfield Characteristics of an Ice Contaminated Aircraft Wing", AIAA 990375, January 1999.

9.) "NPARC Version 3.0 User's Manual", NPARC Alliance, September 1996.
10.) Bragg, M.B., Loth, E., Dunn, T., Lee, S., and Kumar, S.,"EMB120 airfoil with Ice Experiment and Computation (preliminary results)", FAA/NASA briefing, October 1998.

11.) Joint NASA/FAA Airplane Deicing Boot Ice Bridging Workshop held at NASA Lewis Research Center, November 1997. 
Tables

Table 1, Planned Test Matrix

\begin{tabular}{|c|c|c|c|c|c|c|c|c|c|}
\hline Matrix \# & $\begin{array}{c}\mathrm{A} / \mathrm{S} \\
(\mathrm{knots})\end{array}$ & $\begin{array}{l}\text { Total } \\
\text { Temp } \\
\text { (F) }\end{array}$ & $\begin{array}{c}\mathrm{AOA} \\
\text { (deg) }\end{array}$ & $\begin{array}{l}\text { LWC } \\
\left(\mathrm{g} / \mathrm{m}^{3}\right)\end{array}$ & $\begin{array}{l}\text { MVD } \\
(\mu \mathrm{m})\end{array}$ & $\begin{array}{l}\text { Pair } \\
\text { (psia) }\end{array}$ & $\begin{array}{c}\text { DP } \\
\text { (psid) }\end{array}$ & $\begin{array}{l}\text { Time } \\
(\mathrm{min})\end{array}$ & Comments \\
\hline 1 & 172 & & & & & & & & Clean Wake Run \\
\hline 2 & 172 & 30 & 5 & 0.8 & 20 & 37 & 98 & 5 & Baseline series \\
\hline 3 & 172 & 30 & 5 & 0.8 & 40 & 19 & 83 & 5 & Baseline series \\
\hline 4 & 172 & 30 & 5 & 0.52 & 40 & 10 & 33 & 5 & Baseline series \\
\hline 5 & 172 & 30 & 5 & 0.58 & 70 & 8.2 & 32 & 5 & Baseline series \\
\hline 6 & 172 & 30 & 7 & 0.8 & 20 & 37 & 98 & 5 & Higher AOA series \\
\hline 7 & 172 & 30 & 7 & 0.8 & 40 & 19 & 83 & 5 & Higher AOA series \\
\hline 8 & 172 & 30 & 7 & 0.52 & 40 & 10 & 33 & 5 & Higher AOA series \\
\hline 9 & 172 & 30 & 7 & 0.58 & 70 & 8.2 & 32 & 5 & Higher AOA series \\
\hline 10 & 172 & & & & & & & & Clean Wake Run \\
\hline 11 & 172 & & & & & & & & Clean Wake Run \\
\hline 12 & 172 & 30 & 3 & 0.8 & 20 & 37 & 98 & 5 & Lower AOA series \\
\hline 13 & 172 & 30 & 3 & 0.8 & 40 & 19 & 8.3 & 5 & Lower AOA series \\
\hline 14 & 172 & 30 & 3 & 0.52 & 40 & 10 & 33 & 5 & Lower AOA series \\
\hline 15 & 172 & 30 & 3 & 0.58 & 70 & 8.2 & 32 & 5 & Lower AOA series \\
\hline 16 & 172 & 31 & 5 & 0.8 & 20 & 37 & 98 & 5 & Higher Temp series \\
\hline 17 & 172 & 31 & 5 & 0.8 & 40 & 19 & 83 & 5 & Higher Temp series \\
\hline 18 & 172 & 31 & 5 & 0.52 & 40 & 10 & 33 & 5 & Higher Temp series \\
\hline 19 & 172 & 31 & 5 & 0.58 & 70 & 8.2 & 32 & 5 & Higher Temp series \\
\hline 20 & 172 & & & & & & & & Clean Wake Run \\
\hline 21 & 172 & & & & & & & & Clean Wake Run \\
\hline 22 & 172 & 28 & 5 & 0.8 & 20 & 37 & 98 & 5 & Lower Temp series \\
\hline 23 & 172 & 28 & 5 & 0.8 & 40 & 19 & 83 & 5 & Lower Temp series \\
\hline 24 & 172 & 28 & 5 & 0.52 & 40 & 10 & 33 & 5 & Lower Temp series \\
\hline 25 & 172 & 28 & 5 & 0.58 & 70 & 8.2 & 32 & 5 & Lower Temp series \\
\hline 26 & 172 & 26 & 5 & 0.8 & 20 & 37 & 98 & 5 & Lower Temp series II \\
\hline 27 & 172 & 26 & 5 & 0.8 & 40 & 19 & 83 & 5 & Lower Temp series II \\
\hline 28 & 172 & 26 & 5 & 0.52 & 40 & 10 & 33 & 5 & Lower Temp series II \\
\hline 29 & 172 & 26 & 5 & 0.58 & 70 & 8.2 & 32 & 5 & Lower Temp series II \\
\hline 30 & 172 & & & & & & & & Clean Wake Run \\
\hline 31 & 172 & & & & & & & & Clean Wake Run \\
\hline 32 & 172 & 30 & 5 & 0.8 & 20 & 37 & 98 & 10 & Longer Time series \\
\hline 33 & 172 & 30 & 5 & 0.8 & 40 & 19 & 83 & 10 & Longer Time series \\
\hline 34 & 172 & 30 & 5 & 0.52 & 40 & 10 & 33 & 10 & Longer Time series \\
\hline 35 & 172 & 30 & 5 & 0.58 & 70 & 8.2 & 32 & 10 & Longer Time series \\
\hline 36 & 172 & & & & & & & & Clean Wake Run \\
\hline 37 & 172 & 30 & 5 & 0.6 & 100 & 6 & 30 & 5 & Additional SLD series \\
\hline 38 & 172 & 30 & 5 & 0.6 & 120 & 5 & 28 & 5 & Additional SLD series \\
\hline 39 & 172 & 30 & 5 & 0.85 & 175 & 5 & 50 & 5 & Additional SLD series \\
\hline 40 & 172 & 30 & 5 & 0.85 & 270 & 2 & 22 & 5 & Additional SLD series \\
\hline 41 & 172 & 28 & 5 & 0.6 & 100 & 6 & 30 & 5 & Additional SLD series \\
\hline 42 & 172 & 30 & 3 & 0.6 & 100 & 6 & 30 & 5 & Additional SLD series \\
\hline 43 & 172 & 30 & 7 & 0.6 & 100 & 6 & 30 & 5 & Additional SLD series \\
\hline
\end{tabular}


Table 2, As-Run Test Matrix

\begin{tabular}{|c|c|c|c|c|c|c|c|}
\hline Matrix \# & Comments & Date & Run \# & $\begin{array}{l}\text { Repeat } \\
\text { Date }\end{array}$ & $\begin{array}{l}\text { Repeat } \\
\text { Run \# }\end{array}$ & $\begin{array}{l}\text { Repeat\#2 } \\
\text { Date }\end{array}$ & $\begin{array}{l}\text { Repeat\#2 } \\
\text { Run \# }\end{array}$ \\
\hline 1 & Clean Wake Run & $1 / 20 / 98$ & 1 & & & & \\
\hline 2 & Baseline series & $1 / 20 / 98$ & 2 & $1 / 26 / 98$ & 8 & $1 / 26 / 98$ & 9 \\
\hline 3 & Baseline series & $1 / 20 / 98$ & 3 & $1 \longdiv { 2 6 / 9 8 }$ & 6 & $1 / 26 / 98$ & 7 \\
\hline 4 & Baseline series & $1 / 20 / 98$ & 4 & $1 / 26 / 98$ & 4 & $1 / 26 / 98$ & 5 \\
\hline 5 & Baseline series & $1 / 20 / 98$ & 5 & $1 / 26 / 98$ & 2 & $1 / 26 / 98$ & 3 \\
\hline 6 & Higher AOA series & $1 / 21 / 98$ & 2 & $1 / 29 / 98$ & 7 & & \\
\hline 7 & Higher AOA series & $1 / 21 / 98$ & 3 & $1 / 29 / 98$ & 8 & & \\
\hline 8 & Higher AOA series & $1 / 21 / 98$ & 4 & $1 / 30 / 98$ & 2 & & \\
\hline 9 & Higher AOA series & $1 / 21 / 98$ & 5 & $1 / 30 / 98$ & 3 & & \\
\hline 12 & Lower AOA series & $1 / 21 / 98$ & 6 & $1 / 29 / 98$ & 2 & & \\
\hline 13 & Lower AOA series & $1 / 21 / 98$ & 7 & $1 / 29 / 98$ & 3 & & \\
\hline 14 & Lower AOA series & $1 / 21 / 98$ & 8 & $1 / 29 / 98$ & 4 & & \\
\hline 15 & Lower AOA series & $1 / 22 / 98$ & 2 & $1 / 22 / 98$ & 3 & $1 / 29 / 98$ & 5 \\
\hline 16 & Higher Temp series & $1 / 22 / 98$ & 4 & & & & \\
\hline 17 & Higher Temp series & $1 / 22 / 98$ & 5 & & & & \\
\hline 18 & Higher Temp series & $1 / 22 / 98$ & 6 & & & & \\
\hline 19 & Higher Temp series & $1 / 22 / 98$ & 7 & & & & \\
\hline 22 & Lower Temp series & $1 / 22 / 98$ & 8 & $1 / 28 / 98$ & 2 & & \\
\hline 23 & Lower Temp series & $1 / 22 / 98$ & 9 & $1 / 28 / 98$ & 3 & & \\
\hline 24 & Lower Temp series & $1 / 23 / 98$ & 2 & $1 / 28 / 98$ & 4 & & \\
\hline 25 & Lower Temp series & $1 / 23 / 98$ & 3 & $1 / 28 / 98$ & 5 & & \\
\hline 26 & Lower Temp series II & $1 / 23 / 98$ & 4 & $1 / 27 / 98$ & 6 & & \\
\hline 27 & Lower Temp series II & $1 / 23 / 98$ & 5 & 12 & 9 & & \\
\hline 28 & Lower Temp series II & $1 / 23 / 98$ & 6 & $1 / 28 / 98$ & 7 & & \\
\hline 29 & Lower Temp series II & $1 / 23 / 98$ & 7 & $1 / 28 / 98$ & 8 & & \\
\hline 32 & Longer Time series & $1 / 23 / 98$ & 8 & & & & \\
\hline 33 & Longer Time series & $1 / 23 / 98$ & 9 & & & & \\
\hline 34 & Longer Time series & $1 / 23 / 98$ & 10 & & & & \\
\hline 35 & Longer Time series & $1 / 23 / 98$ & 11 & & & & \\
\hline 37 & Additional SLD series & $1 / 27 / 98$ & 2 & & & & \\
\hline 38 & Additional SLD series & $1 / 27 / 98$ & 3 & & & & \\
\hline 39 & Additional SLD series & $1 / 27 / 98$ & 4 & & & & \\
\hline 40 & Additional SLD series & $1 / 27 / 98$ & 5 & & & & \\
\hline 41 & Additional SLD series & $1 / 28 / 98$ & 6 & & & & \\
\hline 42 & Additional SLD series & $1 / 29 / 98$ & 6 & & & & \\
\hline 43 & Additional SLD series & $1 / 30 / 98$ & 4 & & & & \\
\hline 3Deice & $\begin{array}{c}\text { Matrix \#3 } \\
\text { With De-ice @ 5min }\end{array}$ & $1 / 26 / 98$ & 10 & & & & \\
\hline 26Deice & $\begin{array}{c}\text { Matrix \#26 } \\
\text { With De-ice (d) } 2 \mathrm{~min} \\
\end{array}$ & $1 / 27 / 98$ & 7 & & & & \\
\hline 27Deice & $\begin{array}{c}\text { Matrix \#27 } \\
\text { With De-ice @ 2min }\end{array}$ & $1 / 27 / 98$ & 8 & & & & \\
\hline 27Deice & $\begin{array}{c}\text { Matrix \#27 } \\
\text { With De-ice @ 2min and 5min }\end{array}$ & $1 / 27 / 98$ & 9 & & & & \\
\hline 26Deice & $\begin{array}{c}\text { Matrix \#26 } \\
\text { With De-ice @ } 2 \min \text { and } 5 \min \end{array}$ & $1 / 27 / 98$ & 10 & & & & \\
\hline
\end{tabular}




\section{Figures}
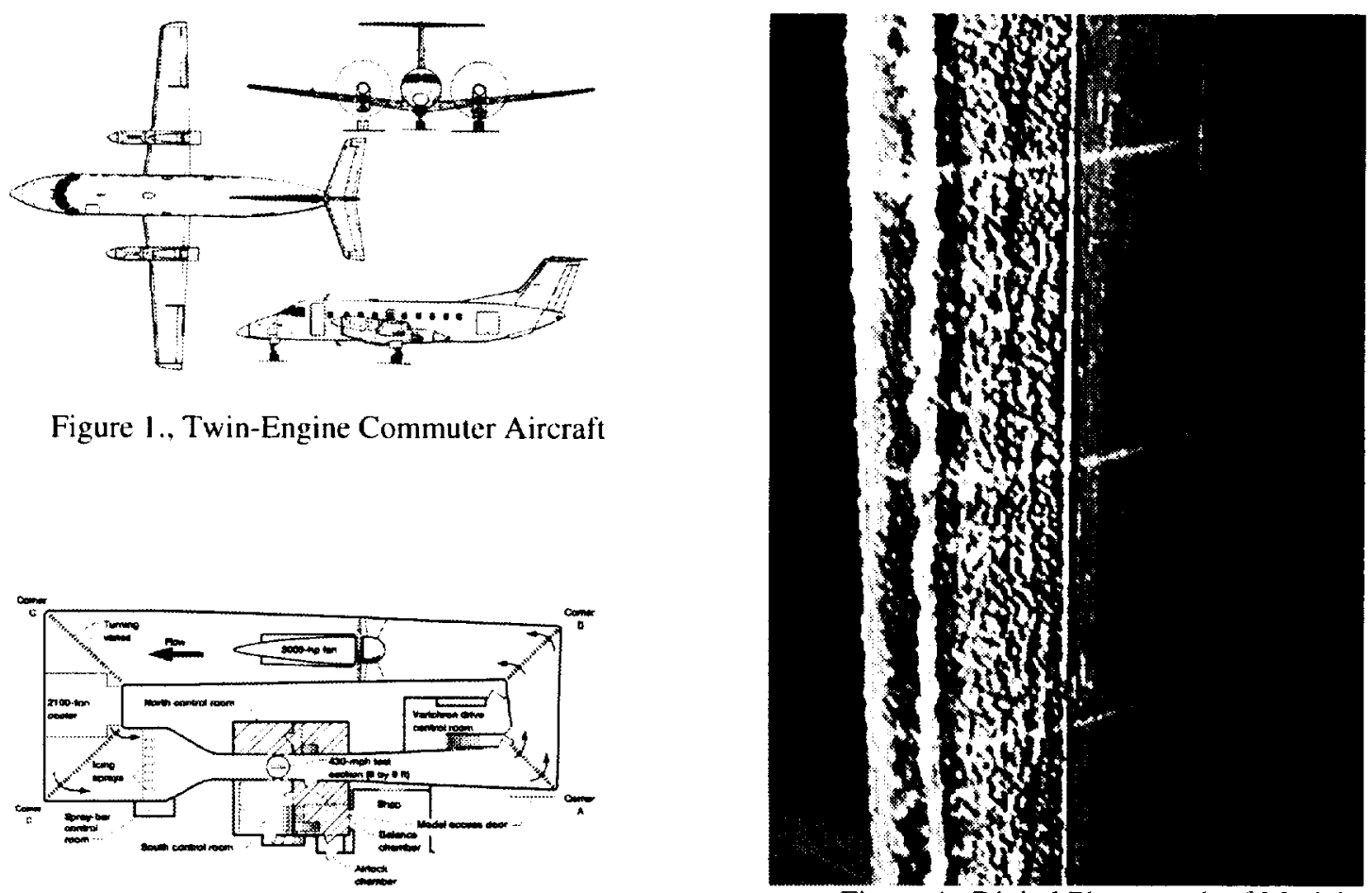

Figure 4., Digital Photograph of Model

Figure 2., Planview of IRT with Ice Accretion

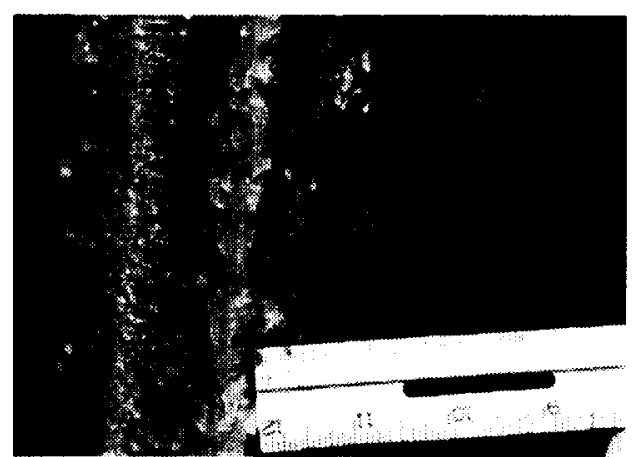

Figure 5., Close-up Film Photograph of Ice Accretion

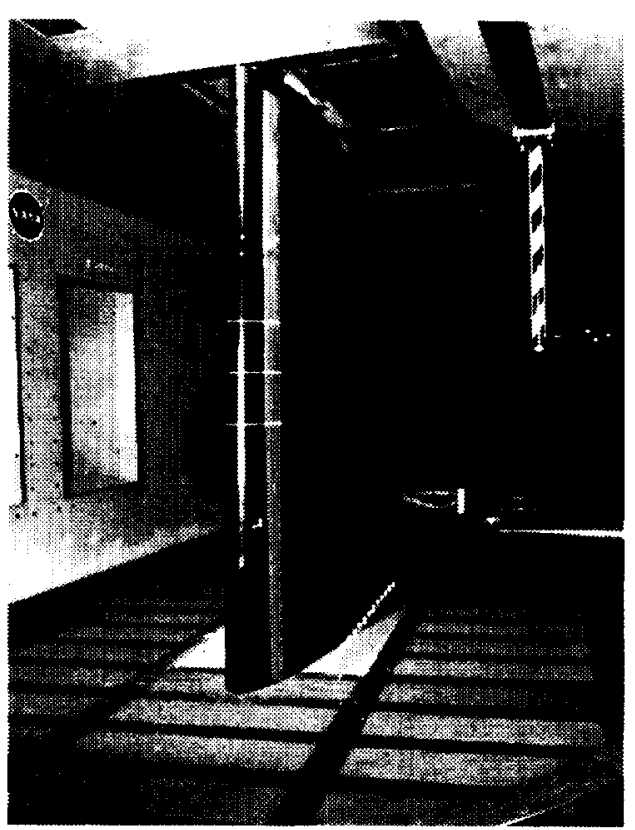

Figure 3., Model installed in IRT 


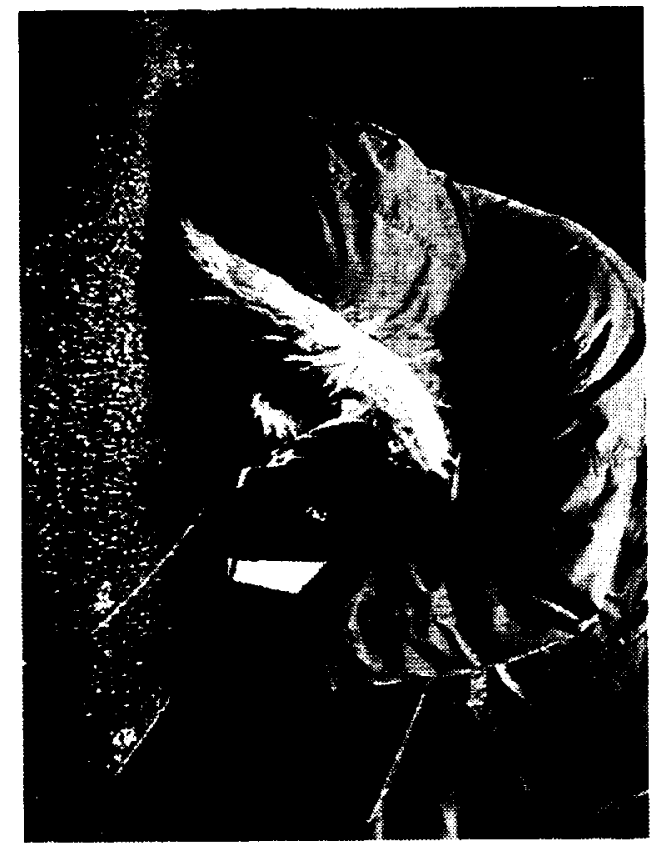

Figure 6., Ice Tracing Technique

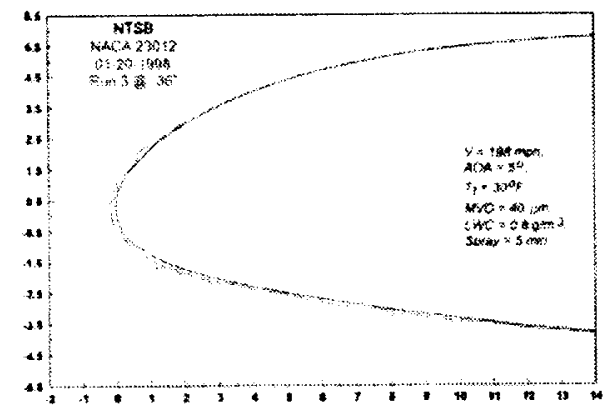

Figure 7., Example Digitized Ice Shape

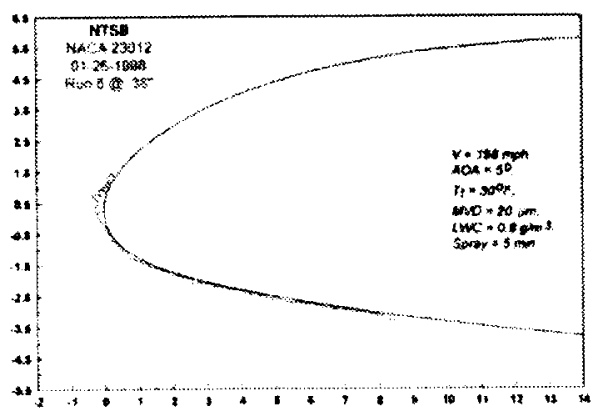

Figure 8., Tracing of Non-Ridge Shape

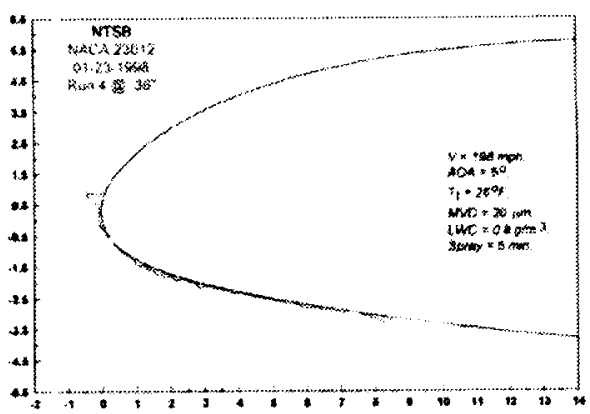

igure 9., Tracing of Ridged Ice Shape

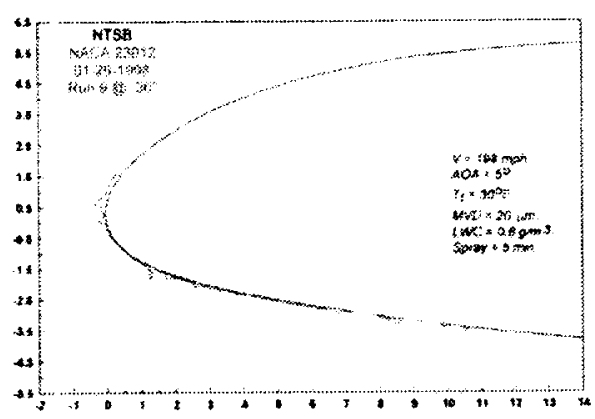

Figure 10., Baseline condition, Matrix number 2 tracing

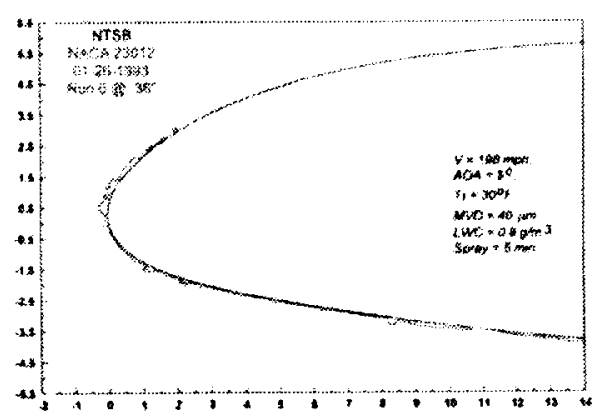

Figure 11., Baseline condition, Matrix number 3 tracing 


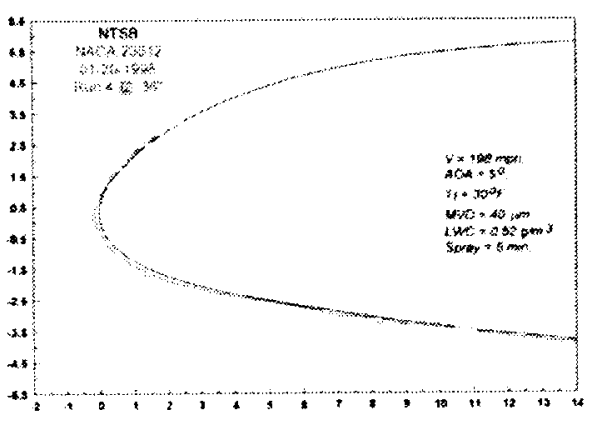

Figure 12., Baseline condition, Matrix number 4 tracing

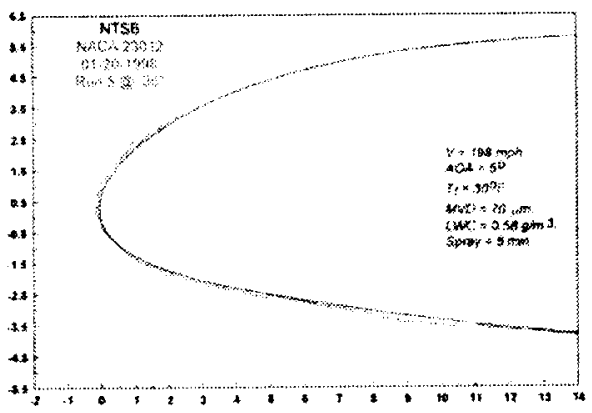

Figure 13., Baseline condition, Matrix number 5 tracing

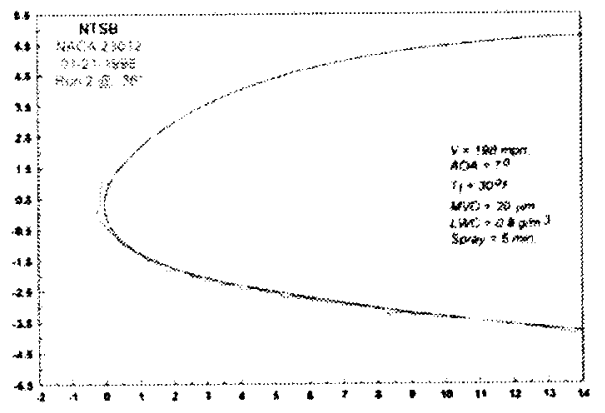

Figure 14., Higher AOA condition. Matrix number 6 tracing

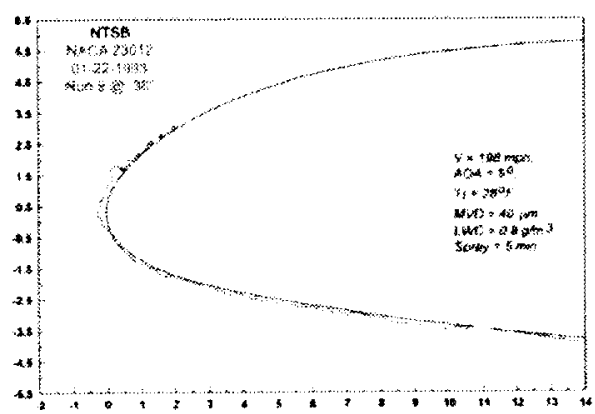

Figure 15., Lower temperature condition, Matrix number 23 tracing

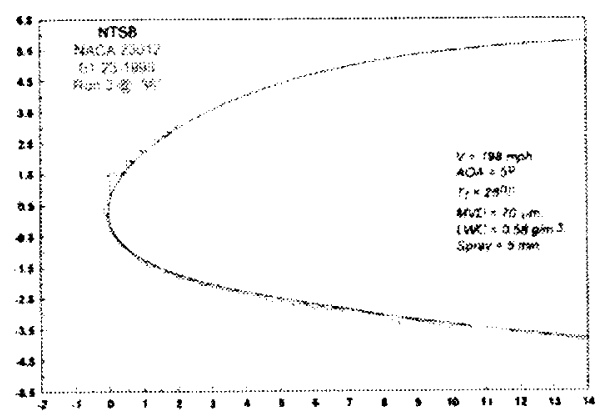

Figure 16., Lower temperature condition, Matrix number 25 tracing

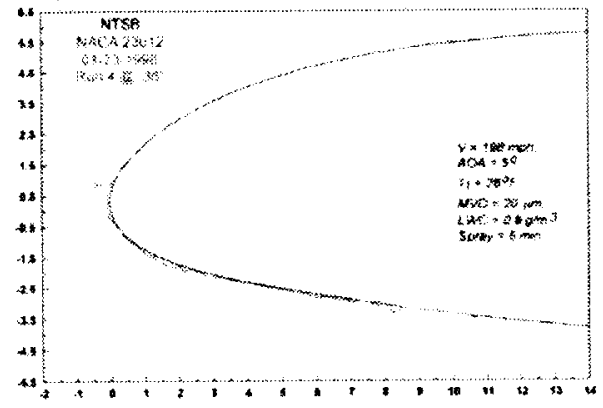

Figure 17., Second lower temperature condition, Matrix number 26 tracing 


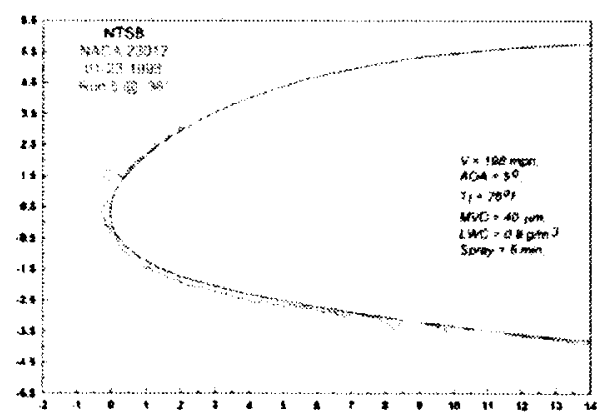

Figure 18., Second lower temperature condition. Matrix number 27 tracing

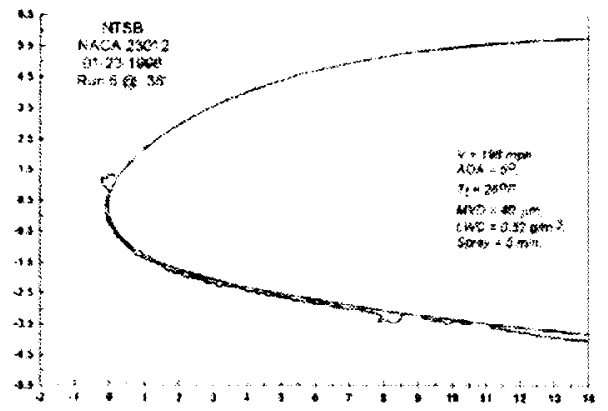

Figure 19., Second lower temperature condition, Matrix number 28 tracing

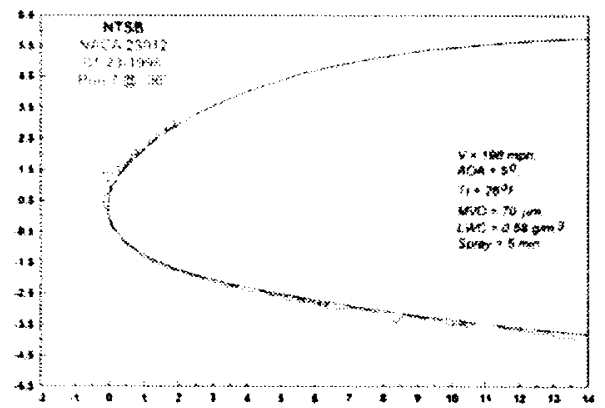

Figure 20., Second lower temperature condition, Matrix number 29 tracing

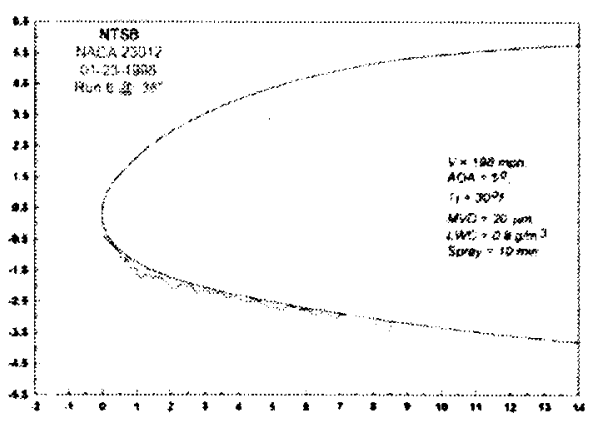

Figure 21., Ten minute accretion condition, Matrix number 32 tracing

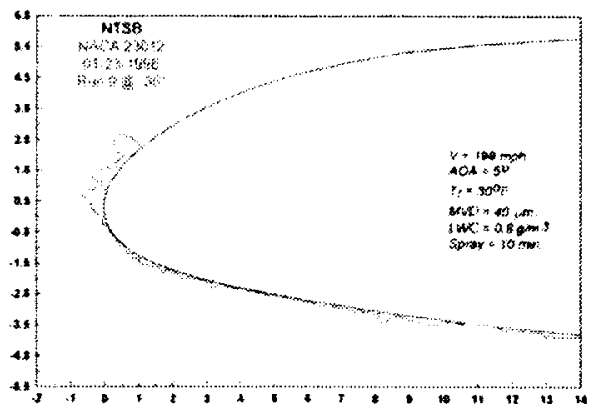

Figure 22.. Ten minute accretion condition, Matrix number 33 tracing

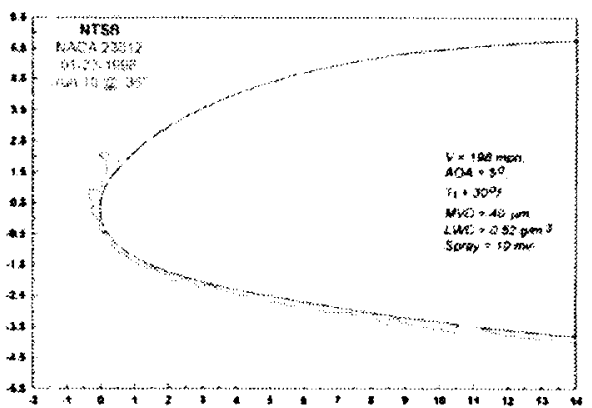

Figure 23.. Ten minute accretion condition, Matrix number $\mathbf{3 4}$ tracing 


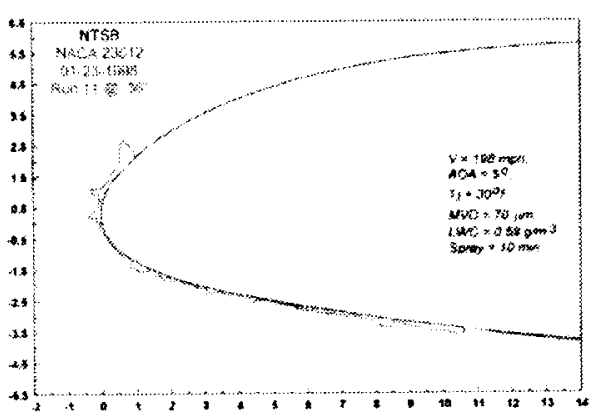

Figure 24., Ten minute accretion condition, Matrix number 35 tracing

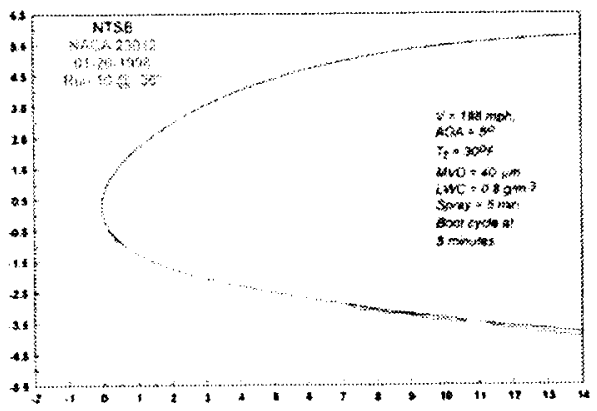

Figure 25., End of spray De-ice, Matrix number 3Deice tracing

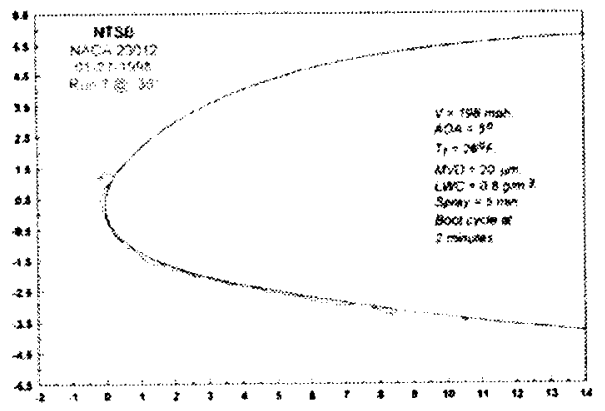

Figure 26., De-ice at 2 minutes of spray, Matrix number 26Deice tracing

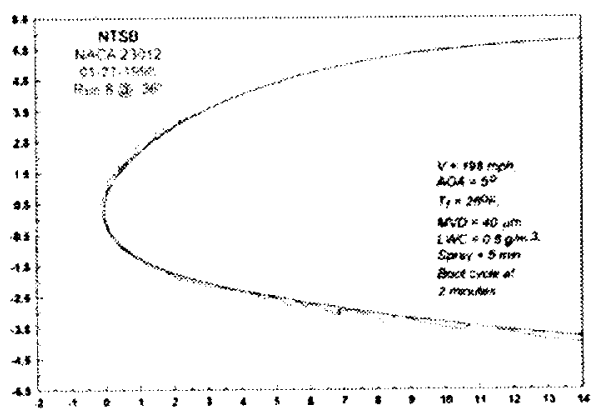

Figure 27., De-ice at 2 minutes of spray, Matrix number 27Deice tracing

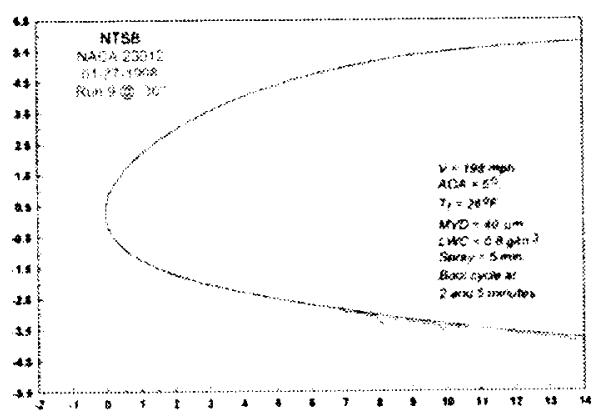

Figure 28., De-ice at 2 minutes and at end of spray, Matrix number 27Deice tracing

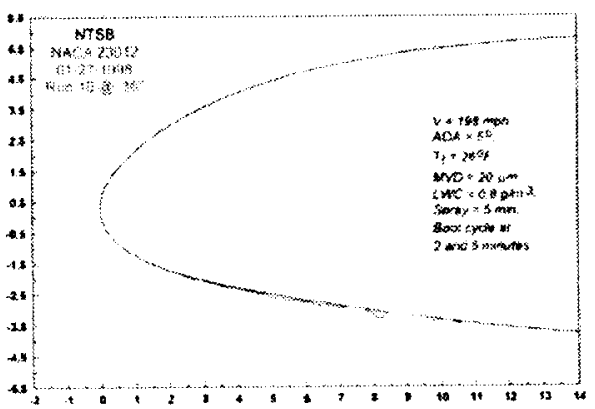

Figure 29., De-ice at 2 minutes and at end of spray, Matrix number 26Deice tracing 


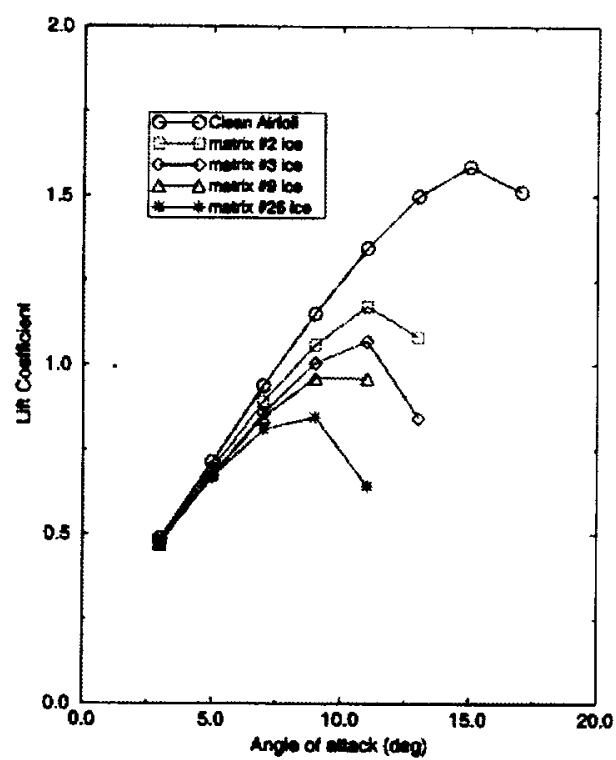

Figure 30., Lift curves for clean airfoil and airfoil contaminated with various ice shapes

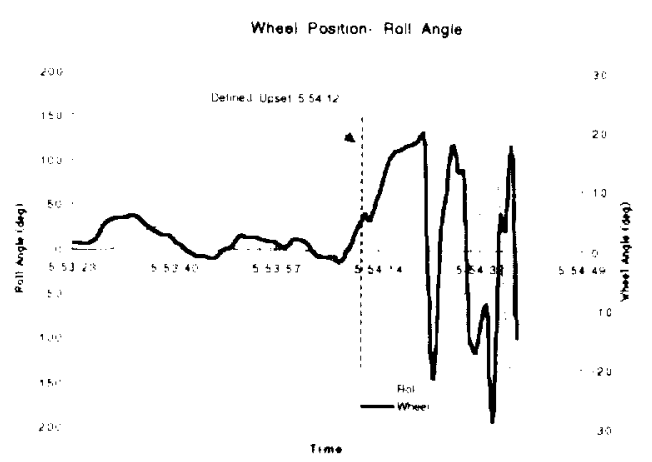

Figure 31., Flight Data Recorder Tracing including upset

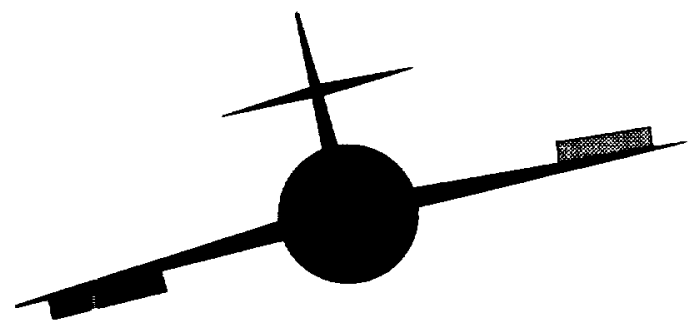

F igure 32., Aircraft and aileron position (not to scale) at upset (view from behind looking forward)

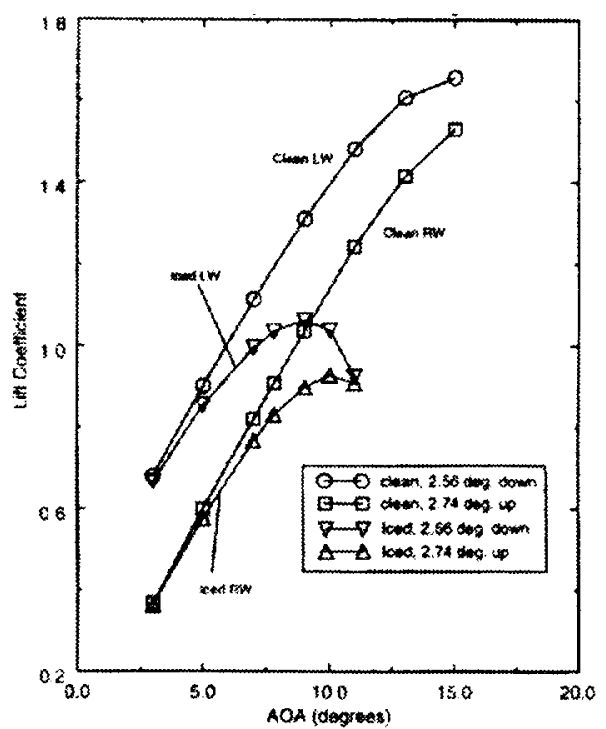

Fig ure 33., Lift curves for clean airfoil and ridge ice shape contaminated airfoil with aileron deflections 


\begin{tabular}{|c|c|c|c|}
\hline \multicolumn{3}{|c|}{ REPORT DOCUMENTATION PAGE } & $\begin{array}{l}\text { Form Approved } \\
\text { OMB No. 0704-0188 }\end{array}$ \\
\hline \multicolumn{4}{|c|}{$\begin{array}{l}\text { Public reporting burden for this collection of information is estimated to average } 1 \text { hour per response, including the time for reviewing instructions, searching existing data sources, } \\
\text { gathering and maintaining the data needed, and completing and reviewing the collection of information. Send comments regarding this burden estimate or any other aspect of this } \\
\text { collection of information, including suggestions tor reducing this burden, to Washington Headquarters Services. Directorate for Intormation Operations and Reports. } 1215 \text { Jefferson } \\
\text { Davis Highway. Sulte } 1204 \text {. Arlington, VA 220202-4302, and to the Office of Management and Budget, Paperwork Reduction Project (0704-0188). Washington, DC 20503. }\end{array}$} \\
\hline 1. AGENCY USE ONLY (Leave blank) & \multicolumn{3}{|c|}{\begin{tabular}{|c|c|}
$\begin{array}{c}\text { 2. REPORT DATE } \\
\text { January } 1999\end{array}$ & $\begin{array}{r}\text { 3. REPORT TYPE AND DATES COVERED } \\
\text { Technical Memorandum }\end{array}$
\end{tabular}} \\
\hline \multicolumn{3}{|c|}{$\begin{array}{l}\text { 4. TITLE AND SUBTITLE } \\
\text { An Experimental and Numerical Study of Icing Effects on the Performance and } \\
\text { Controllability of a Twin Engine Aircraft }\end{array}$} & \multirow{2}{*}{$\begin{array}{l}\text { 5. FUNDING NUMBERS } \\
\text { WU-548-20-23-00 }\end{array}$} \\
\hline \multicolumn{3}{|c|}{$\begin{array}{l}\text { 6. AUTHOR(S) } \\
\text { A. Reehorst, J. Chung, M. Potapczuk, Y. Choo, W. Wright, and T. Langhals }\end{array}$} & \\
\hline \multicolumn{3}{|c|}{$\begin{array}{l}\text { 9. SPONSORING/MONITORING AGENCY NAME(S) AND ADDI } \\
\text { National Aeronautics and Space Administration } \\
\text { Washington, DC } 20546-0001\end{array}$} & $\begin{array}{l}\text { 10. SPONSORING/MONITORING } \\
\text { AGENCY REPORT NUMBER } \\
\text { NASA TM-1999-208896 } \\
\text { AIAA-99-0374 } \\
\text { ICOMP-99-02 }\end{array}$ \\
\hline \multicolumn{4}{|c|}{$\begin{array}{l}\text { 11. SUPPLEMENTARY NOTES } \\
\text { Prepared for the } 37 \text { th Aerospace Sciences Meeting \& Exhibit sponsored by the American Institute of Aeronautics and } \\
\text { Astronautics, Reno, Nevada, January 11-14, 1999. A. Reehorst, M. Potapczuk, and Y. Choo, NASA Lewis Research } \\
\text { Center; J. Chung. Institute for Computational Mechanics in Propulsion, Lewis Research Center, Cleveland, Ohio 44135; } \\
\text { W. Wright and T. Langhals, Dynacs Engineering Company, Inc., 2001 Aerospace Parkway, Brook Park, Ohio } 44142 \text {. } \\
\text { Responsible person, A. Reehorst, organization code 5840, (216)43.3-3938. }\end{array}$} \\
\hline \multirow{2}{*}{\multicolumn{3}{|c|}{$\begin{array}{l}\text { 12a. DISTRIBUTIONAVAILABILITY STATEMENT } \\
\text { Unclassified - Unlimited } \\
\text { Subject Category: } 0.3 \\
\text { This publication is available from the NASA Center for AeroSpace Information, (301) 621-0390. }\end{array}$}} & \multirow[t]{2}{*}{ 12b. DISTRIBUTION CODE } \\
\hline & & & \\
\hline \multicolumn{4}{|c|}{$\begin{array}{l}\text { 13. ABSTRACT (Maximum } 200 \text { words) } \\
\text { In September } 1997 \text { the National Transpontation Safety Board (NTSB) requested assistance from the NASA Lewis Research Center } \\
\text { (LeRC) Icing Branch in the investigation of an aircraft accident that was suspected of being caused by ice contamination. In response to } \\
\text { the request NASA agreed to perform an experimental and computational study. The main activities that NASA performed were LeRC } \\
\text { lcing Research Tunnel (IRT) testing to define ice shapes and 2-D Navier-Stokes analysis to determine the performance degradation that } \\
\text { those ice shapes would have caused. An IRT test was conducted in January 1998. Most conditions for the test were based upon raw and } \\
\text { derived data from the Flight Data Recorder (FDR) recovered from the accident and upon the current understanding of the Meteorologi- } \\
\text { cal conditions near the accident. Using a two-dimensional Navier-Stokes code, the flow field and resultant lift and drag were calculated } \\
\text { for the wing section with various ice shapes accreted in the lRT test. Before the final calculations could be performed extensive } \\
\text { examinations of geometry smoothing and turbulence were conducted. The most signiticant finding of this effort is that several of the } \\
\text { five-minute ice accretions generated in the IRT were found by the Navier-Stokes analysis to produce severe lift and drag degradation. } \\
\text { The information generated by this study suggests a possible scenario for the kind of control upset recorded in the accident. Secondary } \\
\text { findings were that the ice shapes accreted in the IRT were mostly limited to the protected pneumatic boot region of the wing and that } \\
\text { during testing, activation of the pneumatic boots cleared most of the ice. }\end{array}$} \\
\hline \multicolumn{3}{|l|}{ 14. SUBJECT TERMS } & 15. NUMBER OF PAGES \\
\hline \multirow{2}{*}{\multicolumn{3}{|c|}{$\begin{array}{l}\text { Aircraft safety; Aircraft icing; Wind tunnel tests; Computational fluid dynamics; } \\
\text { Aerodynamic characteristics }\end{array}$}} & \\
\hline & & & 16. PRICE CODE \\
\hline
\end{tabular}


